\title{
Techno Economic Analysis of Refractance Window Drying of Fruits: A Case of Small-Medium Scale Agro Processors in Uganda
}

\author{
Faith M. Namayengo ${ }^{1 *}$, Mutumba Raymonds ${ }^{2}$, Aliga Alex ${ }^{3}$, \\ John H. Muyonga ${ }^{2}$
}

${ }^{1}$ Department of Human Nutrition and Home Economics, Kyambogo University, Kampala, Uganda

${ }^{2}$ College of Agricultural and Environmental Sciences, Makerere University, Kampala, Uganda

${ }^{3}$ College of Business and Management Sciences, Makerere University, Kampala, Uganda

\author{
*Corresponding author details: Faith M. Namayengo; namayengof@kyu.ac.ug
}

\begin{abstract}
Uganda produces a variety of fruits, vegetables and herbs with much of it going to waste because of limited post-harvest processing methods. Refractance window drying technology (RWDT) has a potential of producing high quality dried food products from fruits, vegetables and herbs. A techno economic analysis (TEA) was conducted to compare the processing potential of a new hybrid RWD model to existing fruit drying technologies in selected districts of Uganda. Technical and economic data was collected using in-depth interviews with small and medium scale dried fruit processors, farmers and exporters. Comparisons of the technical and economic parameters of the currently used dryers and the hybrid RWD were done to ascertain the competitiveness of hybrid RWD in the local market. Economic analysis was conducted using the cost benefit analysis and payback period tools. Findings indicated the solar box dryer was the commonest and cheapest dryer at USD. 163, while the UNIDO solar hybrid dryer model was the most expensive at USD. 58,378. The UNIDO solar hybrid dryer (USHD) had the highest loading capacity of 1,250 Kg compared to the hybrid RWD and solar box dryer that both had a loading of $30 \mathrm{Kg}$ of whole pineapple per batch. The throughput for the different dryers was found to be $60 \mathrm{Kg}, 7.5 \mathrm{Kg}$ and $0.5 \mathrm{Kg}$ for the USHD, RWD and solar box dryers respectively for a 10 -hour production cycle. The drying time for the solar box dryer was 48 hours compared to 2 hours for the hybrid RWD and 10 hours for the USHD for pineapple flakes per batch. Additionally, the hybrid RWD presented more opportunities for producing a variety of high-quality dried products, including fruit dices, powders, leather and flakes. A recommendation is made for design modification for the hybrid RWD to increase effective drying surface area and throughput.
\end{abstract}

Keywords: refractance window drying; technoeconomic analysis; fruit dying; loading capacity

\section{INTRODUCTION}

There are many available drying technologies in Uganda but most have limited documentation and details about their design, operation, and processing parameters (Menya et al., 2020; Kiggundu et al., 2016). Small scale farmers in Uganda produce a variety of fruits and vegetables which are sold fresh with low monetary returns (Muhanji et al., 2011; Chongtham et al., 2010). Seasonality, high post-harvest losses, limited value addition and low access to market are some of the major challenges encountered by farmers (Tröger et al., 2020; Kikulwe et al., 2018). According to Wakholi et al. (2015), adoption of appropriate preservation technologies could save approximately $68 \%$ of postharvest losses. Use of appropriate and affordable technologies of drying fruit and vegetable for preservation could also increase farmer incomes and enhance industrialization in the communities that process fruits (Okilya et al., 2010; Keatinge et al., 2010). Most drying technologies entail application of high temperatures, which causes discoloration and loss of flavor and bioactive compounds (Hasan et al., 2019; Argyropoulos et al., 2011). This creates an opportunity for the development of other innovative and high-quality technologies that can be used at commercial level in Uganda and beyond. In this regard, Makerere University, Jomo Kenyatta University of Agriculture and Technology, Kenya Industrial Research and Development Institute (KIRDI), TONNET Agro-engineering Company Limited, East Africa Nutraceuticals Ltd (EAN), Food and Nutrition Solutions Ltd (FONUS) and Ministry of Trade, Industry and Cooperatives Uganda are spearheading the bio-innovation of Refractance Window Drying Technology (RWDT) for the 
production of high-quality dried fruit and vegetables. The Refractance window drying is a novel drying technology that dries liquid foods, purees and slices into powders, flakes or sheets with added value (Nindo and Tang, 2007; Nindo et al., 2003; Trivedi et al., 2017; Abul-Fadl and Ghanem, 2011). Being a new technology, there was need to undertake a techno economic analysis (TEA) to establish the performance of the technology in comparison with the existing technologies. The current study therefore is a techno economic analysis of the available technology options aimed at providing information about the viability of RWDT at a commercial level, which would help in development of an alternative and viable technology for drying fruits and vegetables. The overall objective of the TEA was to examine RWDT's commercial viability for local processors of fruits and vegetables in Uganda. Specifically, the TEA was conducted to compare the performance parameters of the RWDT with the existing dryers. It was also done to evaluate the economic performance of the dryer compared to the ones in the market.

\section{METHODS}

A qualitative approach was used to collect data from Kayunga and Luweero districts of Uganda, two areas that dominate pineapple fruit growing and drying activities in the country (Kato, 2007). Semi-structured in-depth interviews were used to collect data for the baseline comparison technologies. Purposive sampling was used to select both the study area and the respondents. Respondents were individuals in the fruit value chain including farmers, small and large scale agro-processors. A total of four processing sites were visited, each with 1-10 processors that operated individually owned dryers. The study also included four processor cooperative groups (KACE, PPI, KHG and KHVCS) and two exporters. The UNIDO solar hybrid dryer (USHD) and the solar box dryers were selected as the baseline technology for comparison with the hybrid RWD. The latter was chosen because it was the functional model found common among the medium scale processors, and the former the most common among small scale processors. Technical and economic data for the RWDT was obtained from the technology development team of Makerere University. Data collected included description of dryer design and main components, capacity, performance parameters including drying time, temperature and final moisture content, range of products, sensory attributes of the different products, costs of operation and production costs of the final products. The processing capacity for all the dryers was obtained basing on a self-reported 10-hour production and comparisons made. An economic analysis was done using the cost benefit analysis (CBA) and payback period (PBP) using the equations below. A technical and economic comparison was then done for all the three dryers and inference made.

Cost benefit analysis: Profits $(\pi)=\sum_{i=1}^{1}(R-C)$

\section{Equation 1}

$$
\text { Payback period }=\frac{\text { Initial outlay }}{\text { cash inflows }}
$$

Equation 2

\section{RESULTS}

\section{Dryer design and operation}

The solar box dryer that solely relies on direct solar energy to dry fruits was found to be the commonest drying technology used by the small-scale fruit processors in the study. The dryers in the study area were made of wooden frames raised about 1 meter off the ground as shown in Figure 1, with the drying chamber enclosed in a polythene sheet that directly acts as the solar collector. At the bottom of the dryer is a dark painted aluminum sheet for build-up of heat within the drying chamber. Access to the drying chamber is through a small window that is closed after loading which acts as the inspection window for the dryer. The solar box dryer comes in three main sizes but the commonest one has a loading capacity of $30 \mathrm{Kg}$ per batch, with each of its three trays yielding $1 \mathrm{Kg}$ of dried fruit in the case of pineapples.

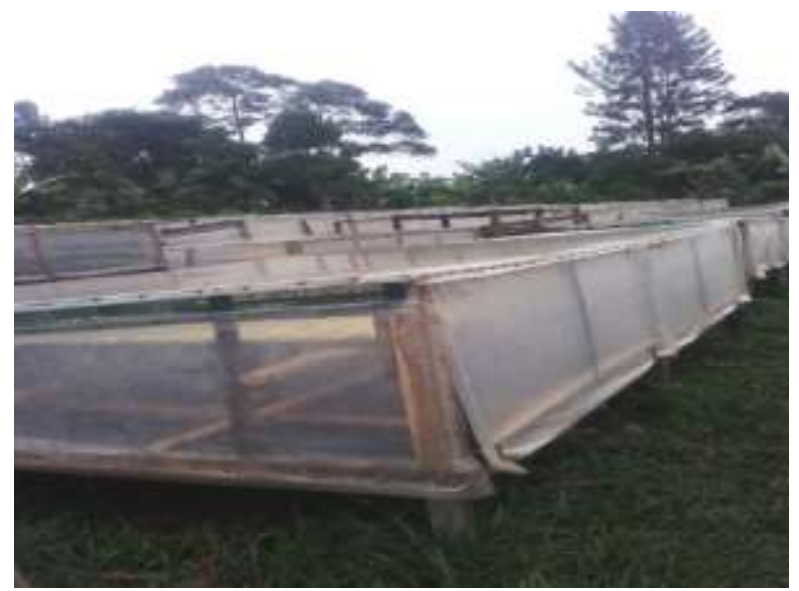

FIGURE 1: The solar box dryer

The solar box dryer operates at an ambient/ existing solar temperature and in the case of pineapples, it produces pineapple flakes at a final moisture content of $13 \%-22 \%$. It was found that solar box dryer was utilized to dry a variety of fruits including pineapples, mangoes, jackfruit, papaya and bananas, into flakes. Fruits are sorted, washed, sliced and loaded onto flat trays while outside the dryer. The trays are then carefully loaded into the drying chamber besides each other through the small window. Drying takes 2 days on average where the trays are left inside the dryer from 10 am on day one to $5 \mathrm{pm}$ the next day for good weather days. The commonly reported drying time for the solar box dryer was 14 hours because most drying will take place between $10 \mathrm{am}-5 \mathrm{pm}$ and minimal drying will take place during the night. Weather change usually cause both discoloration and spoilage of products for solar drying which is a disadvantage in comparison to drying technologies that are not dependent on weather.

The UNIDO solar hybrid dryer (USHD) model, on the other hand, is made up of a collector covered with a colorless glass sheet and a gap of about $8 \mathrm{~cm}$ that forms the air passage between the glass cover and the absorber plate. The collector is oriented at some angle from the horizontal plane in such a way as to maximise the amount of solar radiation received. The collector is connected to the dryer through an insulated tube to discharge drying air throughout the tunnel trays. The USHD employs two modes of energy i.e. solar heating and diesel heating. For the solar heating, a flat galvanized and corrugatedabsorber plate is used as the solar air collector. The trapped air is heated up by solar energy and the hot air is transmitted into the drying chamber.

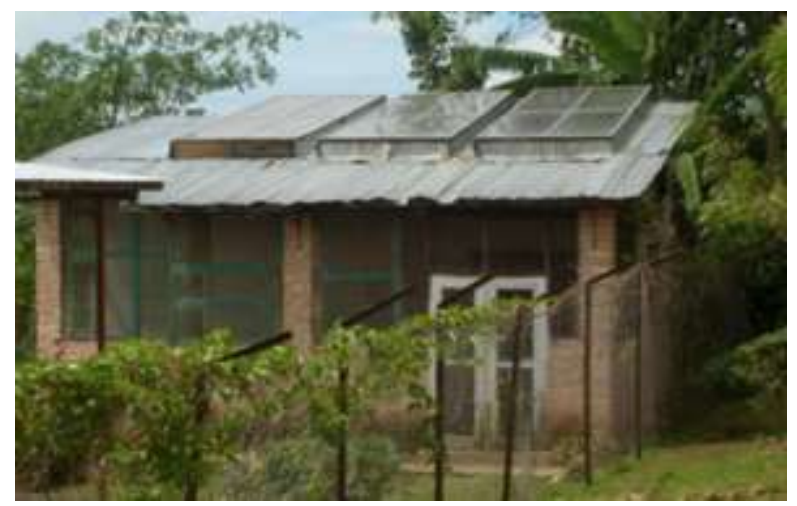

FIGURE 2: The UNIDO Solar Hybrid Dryer (Kiggundu et al., 2016) 
The absorber is insulated from the back side with fiber glass and painted with matt black paint from the front side. The comparison dryer was made up 3 chambers, all of which were loaded and emptied at once. The USHD also employs diesel burners and heated air is transported from the burning chambers into the drying chambers through air ducts that are situated throughout the walls of the dryer using DC fans. During electricity outages, doors and windows are opened up to improve on natural convection since the DC fans would be non-functional. The dryer is mainly used to dry pineapple and mango slices. The USHD is specifically built with three chambers with a total loading capacity of 500 whole pineapples yielding $60 \mathrm{Kg}$ of dried product per batch for an 8-10 Hours production day. The dryer operates within a temperature of $60^{\circ} \mathrm{C}-75^{\circ} \mathrm{C}$ to attain a final moisture content between $10-13 \%$ for pineapple flakes. There is no notable automation or temperature control during drying. The USHD faces a challenge of growth of mold on the chamber walls and a lack of control and monitoring of both moisture and temperature which gives the hybrid RWD an advantage.

The hybrid RWD has four main components; the rocket stove, movable trays, water reservoir, hood and a fixed drying bed. A water bed of 2X1 meters accommodates the hot water that is supplied from the water reservoir. A 7.5 $\mathrm{kW}$ electric water heater element is installed in the drying bed to raise the water temperature from room temperature to the required heating temperature. The dryer has a control system that monitors and regulates the temperatures of the water in tray within the required ranges. Drying temperatures are regulated by a thermostat inserted into the drying bed and monitored using a digital temperature sensor and a mechanical temperature gauge. The dryer is switched on by connecting the dryer adapter to the main connection and then turning on the isolator switch.

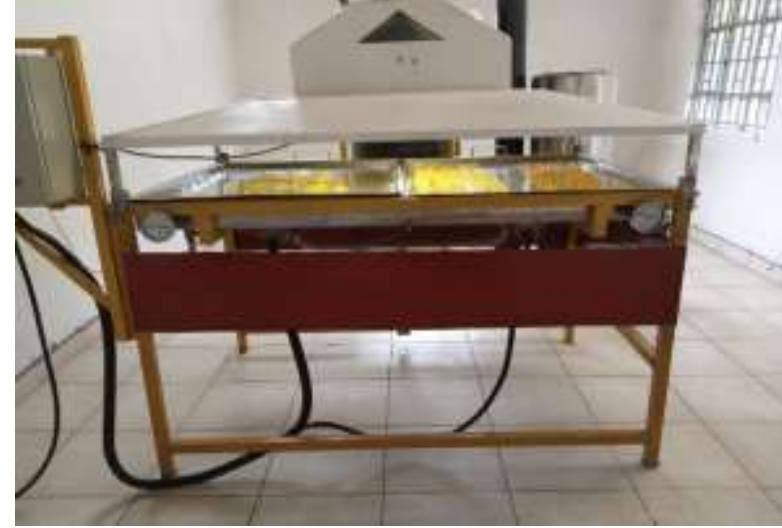

FIGURE 3: The Hybrid Refractance Window Dryer [UG/U/2020/12]

The HybridRWD uses both electric and biomass as alternate sources of energy to heat the water, that dries the food product. The dryer biomass section is composed of a rocket stove that uses firewood as fuel to build up heat in the combustion chamber. Fresh fruit products are evenly loaded onto removable trays, from either inside the dryer or outside depending on convenience and type of product. The static drying trays are made of food grade plastic film (mylar belt) that sit directly onto the hot water troughs. Thermal energy is transferred from the water through the plastic film to the food material through both conduction and infrared radiation. Transmission of infrared radiation stops when the material is dry. The temperature of the product remains relatively low during drying. Air circulation above the plastic film removes moisture from the drying chamber. The RWDT dryers have better energy efficiency than other drying technologies. has Table 1 illustrates the capacity comparison of the hybrid RWD with other dryers per day. From Table 1, it is seen that the hybrid RWD has a larger yield per tray of $3.75 \mathrm{Kg}$ compared to the USHD at $0.44 \mathrm{Kg}$.

TABLE 1: Performance parameters of the UNIDO solar hybrid dryer, hybrid RWD and solar box dryer

The dryer has 2 trays each with a capacity of carrying flakes from 6 whole big sized pineapples (18 $\mathrm{Kg})$ an equivalent of about $7 \mathrm{Kg}$ of fresh fruit slices (FAO, 2005). Fruit drying may take between 2 - 3 hours per batch for pineapple flakes of $4 \mathrm{~mm}$ thickness producing $1.5 \mathrm{Kg}$ at a moisture content of $3 \%-7 \%$. The output of the dryer after a production cycle of 10 hours is $7.5 \mathrm{Kg}$. In the case of pineapple pulp, a drying time of 30 mins to 1.5 hours was reported. The temperature of the water may rise up to $95^{\circ} \mathrm{C}$, with a drying surface temperature of $85^{\circ} \mathrm{C}-9^{\circ} \mathrm{C}$. The dryer uses natural air circulation. The dried product is removed from the mylar belt after cooling. The hybrid RWD is adopted for drying of a variety of products including pineapples, mangoes, jackfruit and passion fruit and is suitable for, producing slices, powder, dices and leather.
The allowance for use of both electricity and bioenergy make the hybrid RWD more versatile in operation for all weather conditions. The RWDT products were found to have acceptable sensory and visual attributes as compared to other dried products on the market. The preliminary sensory evaluation results made using RWDT products as ingredients in foods revealed that the products were acceptable in terms of appearance, aroma, taste and mouth feel. Unlike solar drying technologies that cause loss of flavour and discoloration of the product (Hasan et al., 2019; Argyropoulos et al., 2011), RWDT has been reported to have the advantage of maintaining the bioactive compounds of the fruit products (Ortiz-Jerez et al 2015). A summarized comparison of the operation parameters for UNIDO solar hybrid dryer, solar box dryer and the hybrid RWD is provided in Table 2. 
TABLE 2: Comparison of operation parameters of the UNIDO solar hybrid dryer, hybrid RWD and solar box dryer

\begin{tabular}{|c|c|c|c|}
\hline Parameter & UNIDO solar hybrid dryer & Box Dryer & Hybrid RWD \\
\hline $\begin{array}{l}\text { Drying } \\
\text { temperatures }\end{array}$ & $60-75^{\circ} \mathrm{C}$ Max temperature & $\begin{array}{l}\text { Optimal solar temperature } \\
\text { required }\end{array}$ & $85^{\circ} \mathrm{C}-95^{\circ} \mathrm{C}$ \\
\hline $\begin{array}{l}\text { Colour } \\
\text { (Cream, yellowish) }\end{array}$ & $\begin{array}{l}\text { Attains internationally } \\
\text { accepted colour. However, } \\
\text { power failures may cause } \\
\text { discolorations. }\end{array}$ & $\begin{array}{l}\text { Internationally accepted } \\
\text { colour. Weather changes may } \\
\text { cause discolorations. }\end{array}$ & $\begin{array}{l}\text { Maintains original colour } \\
\text { of the fruit at all times. }\end{array}$ \\
\hline $\begin{array}{l}\text { Final Moisture } \\
\text { content }\end{array}$ & $\begin{array}{l}10-13 \% \text { moisture for } \\
\text { pineapple flakes. }\end{array}$ & $\begin{array}{l}13-22 \% \text { moisture for } \\
\text { pineapple flakes. }\end{array}$ & $\begin{array}{l}3 \%-7 \% \text { final moisture } \mathrm{WB} \\
\text { for pulp. }\end{array}$ \\
\hline $\begin{array}{l}\text { Susceptibility to } \\
\text { weather }\end{array}$ & $\begin{array}{l}\text { Susceptible to weather } \\
\text { changes in terms of product } \\
\text { quality. }\end{array}$ & $\begin{array}{l}\text { Highly susceptible to weather } \\
\text { changes in terms of product } \\
\text { quality. }\end{array}$ & $\begin{array}{l}\text { Not susceptible to weather } \\
\text { changes. }\end{array}$ \\
\hline Automation & No Notable automation system & No automation system & $\begin{array}{l}\text { The water heating system } \\
\text { is automated }\end{array}$ \\
\hline
\end{tabular}

\section{Source: Field data}

\section{Economic Analysis of the hybrid RWD, UNIDO solar} hybrid and the solar box dryer

The study revealed that the UNIDO solar hybrid dryer model was the most expensive to acquire at USD 58,378.
It is 17 times more expensive than the RWD hybrid dryer and 360 times more expensive that the solar box dryer as detailed in Table 3.

TABLE 3: Fixed and variable costs of the UNIDO solar hybrid dryer, hybrid RWD and solar box dryer in USD

\begin{tabular}{|c|c|c|c|c|c|}
\hline Sn & Item & $\begin{array}{l}\text { UNIDO solar } \\
\text { Hybrid dryer }\end{array}$ & Solar Box drier & $\begin{array}{l}\text { RWD Hybrid_ } \\
\text { Electricity }\end{array}$ & $\begin{array}{c}\text { RWD Hybrid } \\
\text { Biomass }\end{array}$ \\
\hline 1 & Electricity & 108.1 & - & 864.9 & - \\
\hline 2 & Water & & 2.7 & 8.1 & 8.1 \\
\hline 3 & Fuel & 739.5 & - & - & 43.2 \\
\hline 4 & Labour & $1,891.9$ & 13.0 & 108.1 & 108.1 \\
\hline 5 & Maintenance cost & 16.2 & 1.4 & 54.1 & 2.7 \\
\hline 6 & $\begin{array}{l}\text { Raw materials } \\
\text { (Pineapples) }\end{array}$ & $14,594.6$ & 162.2 & 518.9 & 518.9 \\
\hline \multicolumn{2}{|c|}{ Total variable costs } & $17,350.3$ & 179.2 & $1,554.1$ & 681.1 \\
\hline \multicolumn{2}{|c|}{ Total fixed costs } & $58,378.4$ & 162.2 & $3,243.2$ & $3,513.5$ \\
\hline \multicolumn{2}{|r|}{ Total costs } & $75,728.6$ & 341.4 & $4,797.3$ & $4,194.6$ \\
\hline
\end{tabular}

\section{Source: Field data}

The solar box dryer was found to be the cheapest to purchase at USD 163, making it the most affordable dryer among them all and the best suited for smaller agroprocessors. Results from equation 2 revealed that working for 30 days per month, a processor would start making profits profits in the third month while using the hybrid RWD dryer and the solar box dryer. This gives the two a seemingly similar and higher economic viability compared to the USHD basing on the payback period method. Table 4 gives summary of the economic analyses of different drying technologies.

TABLE 4: A summary of the economic analyses of the UNIDO, RWD and solar box dryer

\begin{tabular}{cccc}
\hline Item & USHD & Box drier & RWD Hybrid \\
\hline Manufacturing cost (USD) & 58,382 & 162 & 3,514 \\
CBA_30 days (USD) & $-58,354$ & -180 & $-2,976$ \\
Pay back period_30 days & 0.37 years & 0.17 years & 0.24 years \\
\hline
\end{tabular}

\section{Source: Field data}

The results indicated the solar box dryer to have the shortest break-even period compared to USHD and hybrid RWD dryers. Cost benefit analysis showed that the USHD has a negative CBA value after 30 days (USD. -58,364) and the longest payback period of 5 months. However, after breaking even, the USHD may yield more profits per month than to the hybrid RWD and the solar box dryers because of its comparatively higher ability to produce a larger quantity of dried product per unit time.

\section{DISCUSSION}

The USHD model had the highest loading capacity. This is enabled by the dryer's 3 chambers, with a capacity to carry 135 trays. The USHD can thus be used to process large quantity of dried fruit compared to the solar box dryer and the hybrid RWD. The higher loading capacity give it a higher drying capacity, making it more applicable to large scale commercial fruit processing. The large yield per tray of $3.75 \mathrm{Kg}$ compared to the USHD at $0.44 \mathrm{Kg}$ yield per tray of the hybrid RWD compared to USHD implies that the hybrid RWD is able to produce at a more effective capacity than the USHD of the same size with the appropriate design modifications. 
There were many notable design differences between the dryers. For example, the location and size of the side window for the solar box dryer pauses a hindrance to accessing the drying space and to routine cleaning activities. Insects notably flies cannot be removed from the dryer once they enter during the drying process. This is not a problem for the other dryers. Energy source differences among the dryers were also noteworthy. Since it relies entirely on sunlight, the solar box dryer operations may be affected by fluctuating weather conditions that limit its use during rainy weather conditions unlike the hybrid RWD and the USHD. During electricity outages however, product quality may be affected since the DC suction fans function is hampered, limiting the amount of air circulating through the tunnel. Yunus (2011) made similar observation on a hybrid dryer fitted with a biomass backup heater. The USHD is less susceptible to weather changes since it uses diesel burners when solar energy is insufficient. Its use may ensure a more sustainable supply of dried fruits all year round unlike the solar box dryer. Fruit drying using automated technology produces products with better preservation quality compared to non-automated drying technologies (Clary et al., 2007). The hybrid RWD level of automation, which allows water temperatures to be both monitored and controlled, offer an advantage of facilitating production of products of higher keeping and nutritional attributes than other dryers. The ability to control temperature also makes it possible for the hybrid RWD to attain moisture content level of as low as $3-7 \%$ which cannot be done with solar drying. The attainment of low moisture content enables use of hybrid RWD to produce fruit powders and leathers which cannot be achieved by the other technologies. As far as cost is concerned, the high acquisition costs of the USHD puts it at the upper end of the cost spectrum making it unaffordable for many small-scale fruit processors. The cheaper solar box dryer on the other hand is easily accessible to small scale fruit processors who handle smaller quantities to supply a smaller market. This is in line with similar studies by Bisamaza and Banadda (2017) and Ijala et al. (2017) who also observed that solar drying technologies are a cheap and effective way of prolonging shelf life of vegetables and other crops, by small scale agroprocessors in Uganda. The RWD dryer came out as a middle range dryer, with potential for adoption by small and medium scale processors.

\section{CONCLUSIONS}

TEA results highlight the unique ability of the RWDT to produce dried pineapple pulp and mango fruit leather at a low moisture content of as low as $3 \%$. The study also showed that with reliable power supply and consistency in the production process, the RWDT can maintain the original color of the dried fruits. The USHD and solar box dryers may also achieve acceptable color of dried products. However, weather changes may cause discolorations in the final dried product which isn't the case for the hybrid RWD. In terms of capacity, the hybrid RWD has a higher loading capacity compared to the solar box dryer and a higher product yield per tray compared to both the solar box dryer and the USHD. The TEA revealed that the hybrid RWD is commercially viable based on economic results of the PBP and CBA after 30 days. However, the hybrid RWD is more expensive than the box dryer making it more difficult to acquire for small scale processors. Although still more expensive the commonly used solar box dryer, the hybrid RWD has potential for commercial viability. This may be attainable with optimization and design modification that increase the drying capacity to a more commercially competitive scale. This way, the hybrid RWD adoption would contribute to value addition and incomes of farmers and small scale agroprocessors.

\section{ACKNOWLEDGEMENT}

This research was funded by the Bioresources Innovations Network for Eastern Africa Development Programme (BioInnovate Africa) - Grant\#: BA/C1/2017-01_MAK

\section{REFERENCES}

[1] Abul-Fadl, M., \& Ghanem, T. (2011). Effect of Refractance Window (RW) drying method on quality criteria of produced tomato powders as compared to the convection drying method. World Appl.Sci., 15(7), 953-965. https://doi.org/10.12691/ajfst-4-5-4

[2] Argyropoulos, D., MT, K., \& Müller J. (2011). Effect of air temperature and pre-treatment on color changes and texture of dried Boletus edulis mushroom. Drying Technology: An International Journal, 29(16), 1890-1900.

https://doi.org/https://doi.org/10.1080/07373937 .2011 .594194

[3] Bisamaza, M., \& Banadda, N. (2017). Solar drying and sun drying as processing techniques to enhance the availability of selected African indigenous vegetables , Solanum aethiopicum and Amaranthus lividus for nutrition and food security in Uganda, 8(1), 1-6.

[4] Chongtham, I. R., de Neergaard, A., \& Pillot, D. (2010). Assessment of the strategies of organic fruit production and fruit drying in Uganda. Journal of Agriculture and Rural Development in the Tropics and Subtropics, 111(1), 23-34.

[5] FAO. (2005). Pineapple: Post-harvest Operations.

[6] Hasan, M. U., Malik, A. U., Ali, S., Imtiaz, A., Munir, A., Amjad, W., \& Anwar, R. (2019). Modern drying techniques in fruits and vegetables to overcome postharvest losses: A review. Journal of Food Processing and Preservation, 43(12). https://doi.org/https://doi.org/10.1111/jfpp.14280

[7] Ijala, A. R., Alacho, F. O., Ogwang, S. B., Thomas, A., Aseere, G., \& Otim-nape, G. W. (2017). Evaluating Low Cost and Sustainable High Quality Cassava Drying Technologies among Small and Medium Processors in Uganda, 7, 453-457. https://doi.org/10.17265/2159-5828/2017.09.005

[8] Kato, J. (2007, November 11). Luweero picks pineapple crop to fight poverty. New Vision. Retrieved from https://www.newvision.co.ug/news/1219747/luw eero-picks-pineapple-crop-fight-poverty

[9] Keatinge, J. D. H., Waliyar, F., Jamnadas, R. H., Moustafa, A., Andrade, M., Drechsel, P., ... Luther, K. (2010). Relearning old lessons for the future of foodby bread alone no longer: Diversifying diets with fruit and vegetables. Crop Science, 50(April), S-51-S-62. https://doi.org/10.2135/cropsci2009.09.0528

[10] Kiggundu, N., Wanyama, J., Galyaki, C., Banadda, N., Muyonga, J. H., Zziwa, A., \& Kabenge, I. (2016). Solar fruit drying technologies for smallholder farmers in Uganda, A review of design constraints and solutions. Agricultural Engineering International: CIGR Journal, 18(4), 200-210. Retrieved from http://www.cigrjournal.org

[11] Kikulwe, E. M., Okurut, S., Ajambo, S., Nowakunda, K., Stoian, D., \& Naziri, D. (2018). Postharvest losses and their determinants: A challenge to creating a sustainable cooking banana value chain in Uganda. Sustainability (Switzerland), 10(7), 1-19. https://doi.org/10.3390/su10072381 
[12] Menya, J., Tumutegyereize, P., Kabenge, I., \& Kigozi, J. (2020). Performance evaluation of cassava drying technologies: a case study from Uganda. MOJ Food Processing \& Technology, 8(2), 46-51. https://doi.org/10.15406/mojfpt.2020.07.00241

[13] Muhanji, G., Roothaert, R. L., Webo, C., \& Stanley, M. (2011). African indigenous vegetable enterprises and market access for small-scale farmers in East Africa. International Journal of Agricultural Sustainability, 9(1), 194-202. https://doi.org/10.3763/ijas.2010.0561

[14] Nindo, C. I., Feng, H., Shen, G. Q., Tang, J., \& Kang, D. H. (2003). Energy utilization and microbial reduction in a new film drying system. Journal of Food Processing and Preservation, 27(2), 117-136. https://doi.org/10.1111/j.17454549.2003.tb00506.x

[15] Nindo, C. I., \& Tang, J. (2007). Refractance window dehydration technology: A novel contact drying method. Drying Technology, 25(1), 37-48. https://doi.org/10.1080/07373930601152673

[16] Okilya, S., Mukisa, I. M., \& Kaaya, A. N. (2010). Effect Of Solar Drying On The Quality And Acceptability of Jackfruit Leather. Electronic Journal of Environmental, Agricultural \& Food Chemistry, 9(1), 1-11.
[17] Ortiz-Jerez, M. J., Gulati, T., Datta, A. K., \& OchoaMartínez, C. I. (2015). Quantitative understanding of Refractance Window ${ }^{\mathrm{TM}}$ drying. Food and Bioproducts Processing, 95, 237-253. https://doi.org/10.1016/j.fbp.2015.05.010

[18] Trivedi, M., Venecia, D., Shitut, J., \& Srivastav, S. (2017). Refractance Window Technology - A Promising Drying Technique for the Food Industry, $4(1), 6-16$.

[19] Tröger, K., Lelea, M. A., Hensel, O., \& Kaufmann, B. (2020). Re-framing post-harvest losses through a situated analysis of the pineapple value chain in Uganda. Geoforum, 111(October 2019), 48-61. https://doi.org/10.1016/j.geoforum.2020.02.017

[20] Wakholi, C., Cho, B.-K., Mo, C., \& Kim, M. S. (2015). Current State of Postharvest Fruit and Vegetable Management in East Africa. Journal of Biosystems Engineering, 40(3), 238-249. https://doi.org/10.5307/jbe.2015.40.3.238

[21] Yunus, Y. B. M. (2011). Development And Analysis Of Hybrid Solar Dryer With Biomass Backup Heater. (Masters dissertation) Universiti Teknologi Petronas. Retrieved from utpedia.utp.edu.my/3060/1/Msc__Yusheila.pdf 